Article

\title{
The Impact of Workplace Disability Facilities on Job Retention Wishes among People with Physical Disabilities in South Korea
}

\author{
Eun Jung Kim ${ }^{1}$, Inhan $\mathrm{Kim}^{2}$ and Mi Jeong Kim ${ }^{3, * 0}$ \\ 1 Asian Demographic Research Institute, Shanghai University, Shanghai 200444, China; \\ uwcsea0620@hotmail.com \\ 2 Department of Architecture, Kyung Hee University, Yongin 17104, Korea; ihkim@khu.ac.kr \\ 3 School of Architecture, Hanyang University, Seoul 04763, Korea \\ * Correspondence: mijeongkim@hanyang.ac.kr; Tel.: +82-2-2220-1249
}

Received: 31 July 2020; Accepted: 9 September 2020; Published: 11 September 2020

\begin{abstract}
The 2030 UN Agenda for Sustainable Development aims to end poverty "in all forms" and achieve sustainable development by 2030, while ensuring that "no one is left behind", including people with disabilities. Disability is referenced eleven times in the Agenda. Disabled people face high risks of poverty because of barriers such as lack of workplace disability facilities. The goal of the study was to examine how workplace disability facilities affect job retention plans among workers with physical disabilities in South Korea and how perceived workplace safety and work satisfaction act as mediators. The 2018 Panel Survey of Employment for the Disabled was used, and we examined 1023 workers with physical disabilities. Path analysis was used to examine the relationships. Results showed that workers whose workplaces provided more disability facilities were significantly more likely to perceive their workplaces as safe and had higher work satisfaction; hence, they were more likely to wish to maintain their present jobs than those whose workplaces offered fewer facilities. However, many workplaces in Korea did not provide any disability facilities. The study provides empirical evidence to support development of policies for improved workplace facilities and work environments for disabled people, in accordance with the UN Agenda.
\end{abstract}

Keywords: people with physical disabilities; job retention; path analysis; perceived workplace safety; workplace disability facilities; work satisfaction

\section{Introduction}

In September 2015, the United Nations (UN) General Assembly launched the 2030 Agenda for Sustainable Development, which committed the UN member States to eradicate poverty "in all forms" and achieve sustainable development by 2030, while ensuring that "no one is left behind" [1]. The new Agenda pledged to "endeavor to reach the furthest behind first" [2]. In practice, this means taking explicit action to end extreme poverty, curb inequalities, confront discrimination, and fast-track progress for the furthest behind, including people with disabilities, by setting 17 Sustainable Development Goals (SDGs). Disability is referenced explicitly 11 times in the 2013 Agenda in parts related to education (SDG 4), employment (SDG 8), and inequality (SGD 10) [3]. In 2018, the UN released the first flagship report on disability and sustainability, "Realization of the Sustainable Development Goals by, for and with persons with disabilities" [4]. The report demonstrates that people with disabilities are at a disadvantage with respect to achievement of most Sustainable Development Goals and urges States to ensure full and equal participation of disabled people in society and create enabling environments by, for, and with people with disabilities, in line with the UN Convention on the Rights of Persons with 
Disabilities (CRPD). The UN has long identified "accessibility" as a priority in measures promoting equal opportunities for people with disabilities [5].

As a member state of the UN and a state party to the UNCRPD, in 2018, the South Korean (hereafter referred to as Korea) government set 17 goals and 122 targets (i.e., Korea Sustainable Development Goals; KSDGs) in accordance with the 2030 UN SDGs. The 122 targets include increasing fair work opportunities for people with disabilities [6]. Employment is an important means of securing economic stability and buffer against falling into poverty. Yet, in 2019, the employment rate of disabled people in Korea was 34.5\%, substantially lower than the national average employment rate of $60.9 \%[7,8]$. Lack of appropriate workplace disability accommodation facilities, such as wheelchair ramps and accessible toilets, makes it difficult for people with disabilities to find and/or maintain work [9].

In Korea, the "Act on the Guarantee of Convenience Promotion of Persons with disabilities, Senior citizens, Pregnant women and Nursing mothers" stipulates building guidelines and rules, including specific details for disability accommodation design features (i.e., doors must have a minimum width of $80 \mathrm{~cm}$, curb height should be below $6-15 \mathrm{~cm}$ and must be in a different color from the floor, and wheelchair ramp slopes must have a 4.8-degree angle, etc.) [10]. In 2015, the Korean government revised the Act and announced the "Disability Safety Comprehensive Measure Guidelines" to improve building accessibility for people with disabilities [11]. In the revised Act, from 2015, all public buildings in Korea have been required by law to acquire the Barrier-Free (BF) Environment Certification and from 2018, differential floor-area ratio certification fees are charged based on the BF grades [11]. However, private buildings except for factories larger than $500 \mathrm{~m}^{2}$ are exempt from these policies [11] and therefore, many workplaces still lack appropriate disability accommodation features and structures in Korea, which prevents disabled people from fully participating in economic activities.

There have been numerous comparison studies of disabled and nondisabled populations and their employment outcomes [12-15]. However, to the best of our knowledge, there have only been two empirical studies on workplace disability facilities and how they affect disabled workers' job decisions and behaviors in Korea. First, Lee and Seo (2014) [9] examined how workplace disability accommodation facilities impact disabled workers' work satisfaction and job retention years (i.e., years worked in the same workplace) and discovered that disabled workers whose workplaces had more accommodating features and structures had significantly higher work satisfaction and thus, worked longer years than those whose workplaces had fewer of these features and structures. They found that work satisfaction had a significant mediating effect between workplace disability accommodations and job retention years. Second, Kim et al. (2014) [16] examined the relationship between workplace accommodation facilities and disabled workers' perceived workplace safety and job retention years. They discovered that disabled workers whose workplaces were more accommodating were significantly more likely to perceive their workplaces as safer, and that these workers were thus more likely to work more years in the same workplaces than those whose workplaces were less or not accommodating.

While both studies are informative, they have two limitations. First, they examined job retention by years worked in the present job. They overlooked the fact that some people who are satisfied with their work environments and whose workplaces provide appropriate disability accommodation facilities may still have shorter periods of job retention because they have recently joined the firms, which undermines the credibility of the study results. Second, both studies examined all disabled workers, including the mentally disabled, for whom accessible building features and structures have less relevance.

The purpose of this study was to address these gaps in the literature. The present study examined how workplace disability accommodation features and structures affect job retention plans (i.e., whether one wishes to maintain the current job in the future) among disabled workers with physical disabilities. We decided to focus on job retention plans because they reflect individuals' voluntary choices and are unaffected by employment start dates. We focus on workers with physical disabilities because workplace disability accommodation features and structures in Korea are geared primarily toward people with physical disabilities. We empirically examined how workplace disability 
facilities affect disabled workers' job retention plans, and based on Lee and Seo's (2014) [9] and Kim et al.'s (2014) [16] studies, we examined how perceived workplace safety and work satisfaction mediate this relationship using path analysis. Findings from this study provide important insights into understanding workplace disability accommodation features and structures, their impact on employment among disabled people in Korea, and in-built environments for people with disabilities in Korea.

\section{Literature Review}

Until the 1960s, the traditional approach to disability viewed it as an individual deficit that called for medical assistance and a condition that exempted a disabled person from participating in the labor market. However, after 50 years, a more progressive social model approach was developed, which views disability not as a deficit but rather from a minority identity perspective [17]. It reflected a positive progression towards a "portrait of disabled people as capable and fostered a shift from a conception of disability as an unfavorable condition of inability to enhancement of diversity as a resource in work environments, a conception retained by the Disability Management perspective" [18] (p. 3). In the social model, disability is a consequence of social discrimination, and therefore, the removal of barriers that restrict disabled people from fully integrating into mainstream society is important [17].

Article 27 of the UNCRPD recognizes the rights of people with disabilities to work on an equal basis. State Parties are obligated to safeguard and promote the realization of disabled people's right to work, including providing safe and healthy working conditions (art. 27.1. (b)) and ensuring that reasonable accommodation is provided in the workplace (art. 27.1.(i)) [5].

Disabled workers are at increased risk of occupational injuries [19-21]. They are at greater risk of being injured and they are likely to be more severely injured than nondisabled workers. Therefore, workplace safety is especially important for disabled workers. A key function of workplace disability facilities is to enhance accessibility to work and promote a safe and healthy work environment for disabled workers [22,23]. Numerous studies have examined the impact of workplace disability facilities and work safety and found a positive and significant association between the two variables [24-26]. In Korea, Park et al. (2010) [24] examined the relationship between workplace disability facilities and perceived work safety and found that disabled workers who worked in workplaces that had more disability facilities were more likely to perceive their workplaces as safe than workers with fewer or no facilities. Also, they found that perceived work safety had the most significant influence on work satisfaction among disabled workers. Similar results were also found in Lee and Shin's (2019) [27] study, which used path analysis to examine the relationship between workplace disability facilities, perceived workplace safety, and work satisfaction among disabled workers. They found that individuals who worked in companies that provided more disability facilities were significantly more likely to perceive their workplaces as safe, and therefore, had higher work satisfaction than those who worked in companies that provided fewer disability facilities (i.e., treating perceived workplaces as a mediator).

With regard to workplace disability facilities and job retention, to date, there have only been two studies that have examined the relationship between the two variables in Korea (as mentioned in the introduction). Both studies indicated a significant positive relationship. Kim et al. (2014) [16] included perceived work safety as a mediator and Lee and Seo (2014) [9] included work satisfaction as a mediator in their models. However, perceived work safety and work satisfaction are significantly correlated in Korea as indicated above in Park et al. (2010) [24] and Lee and Shin (2019) [27] studies. As a result, the impact of workplace facilities on job retention is likely to be mediated through not only each individual variable but also by the correlation between the two variables. Hence, in this study, we examined how workplace disability facilities influence disabled workers' job retention plans, including both perceived workplace safety and work satisfaction as mediators in our model. Based on the literature review, we hypothesize that individuals who work in companies that provided more disability facilities are more likely to perceive their workplaces as safer and hence, are more likely 
to have higher work satisfaction, and therefore, wish to work in their present workplaces (double mediating effect).

\section{Methods}

\subsection{Data}

Data for this study were drawn from the 2018 Panel Survey of Employment for the Disabled (PSED) version 2 [28]. The PSED is an annual national survey aimed at examining and addressing the economic activities of the Korean disabled population. The survey consists of demographic-, economic-, and employment-related questions. The initial version of the PSED was first conducted in 2007 and ended in 2015. The second version of PSED was developed in 2016 with a new sample and questionnaire. PSED version 2 uses a multi-stage, stratified clustered random sampling design to survey registered disabled people (i.e., those defined as disabled under the Korean Act on Welfare of Persons with Disabilities and are registered in the welfare system) aged 16 to 65 across the nation. The 2018 PSED surveyed a total of 4104 registered disabled people representative of the national disabled population. In the present study, we decided to use PSED because it is the only nationwide survey that includes diverse information about disabled workers and their workplace environments, including information on disability accommodation facilities.

\subsection{Sample}

For this study, our analytical sample was wage-earning working people with physical disabilities. We limited disabled workers to wage-earning disabled workers and excluded the self-employed because most self-employed workers have the authority to alter their work environments if they wish to, unlike wage-earners. Also, in this study, we decided to focus on people with physical disabilities because the workplace modification variables in PSED were primarily specific to design changes intended to accommodate physical mobility issues, such as removal of curbs and steps, accessible bathrooms, adequate entrance and doorway space, reserved parking space for the disabled, and suitable pavement for disabled pedestrians. In this study, "physical disabilities" refers to physical conditions that affect a person's mobility, physical capacity, stamina, or dexterity [29]. These can include spinal cord injuries, multiple sclerosis, cerebral palsy, spina bifida, amputation, muscular dystrophy, cardiac conditions, paralysis, polio, stroke, and many other conditions. The Korean Act on Welfare of Persons with Disabilities (art. 2) [30] classifies disability into 15 types and PSED groups them into four categories based on their impairment characteristics: Physical disability, sensory disability, intellectual disability, and internal organ-related disability (i.e., cardiovascular, respiratory, diabetes, etc.). This study selected those who reported having physical disabilities in the PSED, as defined therein. Based on these criteria, for this study, a total sample of 1023 wage-earning disabled workers with physical disabilities was extracted from the 2018 PSED version 2.

As presented in Table 1, on average, workers in our sample were 50 years old and had a monthly salary of KRW 2,210,000 (approximately US \$1800), substantially lower than the average Korean wage-earning worker's monthly salary of KRW 2,970,000 (approximately US \$2500) [31]. The average number of family members was 2.9 and respondents worked an average of $8 \mathrm{~h}$ and $10 \mathrm{~min}$ per day. Approximately $18 \%$ of the respondents were the head of their household. The majority of the respondents were male $(80 \%)$, married or in a civil partnership $(71 \%)$, perceived themselves as middle-class, and reported to have a mild disability $(87 \%)$. Approximately $54 \%$ of respondents worked as non-regular workers, while $47 \%$ reported their highest educational attainment as a high school degree, and $83 \%$ worked in companies with fewer than 100 employees. 
Table 1. Description of the sample $(\mathrm{N}=1023)$.

\begin{tabular}{|c|c|}
\hline Characteristics & Mean (SD) \\
\hline Age & $50.47(9.86)$ \\
\hline Monthly salary & $2,210,500(1,377,800)$ \\
\hline Household family number & $2.87(1.23)$ \\
\hline \multirow[t]{2}{*}{ Work hour per day } & $8.16(2.58)$ \\
\hline & n (\%) \\
\hline \multicolumn{2}{|l|}{ Employment contract type } \\
\hline Regular & $476(46.5 \%)$ \\
\hline Non-regular & $548(53.6 \%)$ \\
\hline \multicolumn{2}{|l|}{ Gender } \\
\hline Male & $813(79.5 \%)$ \\
\hline Female & $209(20.5 \%)$ \\
\hline \multicolumn{2}{|l|}{ Marital Status } \\
\hline Married or civil partnership & $729(71.3 \%)$ \\
\hline Others & $293(28.7 \%)$ \\
\hline \multicolumn{2}{|l|}{ Head of the household } \\
\hline No & $838(81.9 \%)$ \\
\hline Yes & $185(18.1 \%)$ \\
\hline \multicolumn{2}{|c|}{ Self-perceived household economic class } \\
\hline Low-class & $291(28.4 \%)$ \\
\hline Middle-class & $568(55.5 \%)$ \\
\hline High-class & $165(16.1 \%)$ \\
\hline \multicolumn{2}{|l|}{ Education attainment } \\
\hline Middle school degree or lower & $248(24.2 \%)$ \\
\hline High school degree & $479(46.8 \%)$ \\
\hline College degree or higher & $297(29.0 \%)$ \\
\hline \multicolumn{2}{|l|}{ Company size (number of employees) } \\
\hline 10 or less & $423(41.4 \%)$ \\
\hline $11-100$ & $423(41.4 \%)$ \\
\hline More than 100 & $174(17.1 \%)$ \\
\hline \multicolumn{2}{|l|}{ Disability severity $^{a}$} \\
\hline Mild disability & $892(87.2 \%)$ \\
\hline Severe disability & $131(12.8 \%)$ \\
\hline
\end{tabular}

\begin{abstract}
Note: Survey weights were applied to represent the population parameters. ${ }^{a}$ The PSED defined persons with severe disability as those who meet the criteria for disability classification grades 1, 2, or 3 under the Korean Act on Welfare of Persons with Disabilities and have either brain, sight, mental, heart, respiratory, cerebral palsy, or arm-related physical impairments. All other categories are defined as a mild disability. The present study thus used the PSED definition of disability and did not construct this variable.
\end{abstract}

\title{
3.3. Measures
}

Workplace disability facility (exogenous variable): The effect of workplace disability accommodation facilities was examined based on the number of disability facilities provided at workplaces. The PSED asked respondents whether each of the following five particular facilities was installed or provided at their workplace: (1) Adequate clear space on pavements for wheelchairs and scooters; (2) reserved parking spaces for disabled people; (3) removal of vertical level changes (e.g., curbs, steps, ruts, gutters, etc.); (4) disability bathrooms; and (5) adequate entrance and doorway space width for wheelchairs. Respondents were asked to report a binary "yes" or "no" outcome. In this study, we summed the facility scores and treated the variable as a count continuous variable ranging $0-5$. The Cronbach's alpha test score, which reports how coherent a set of items are as a group, was 0.94 , indicating high internal consistency within the five items (relative to a threshold of 0.8 ).

Perceived workplace safety (mediator): The PSED asked respondents "how safe they feel their workplace is" using a four-point Likert scale (1: very dangerous— 4 : very safe). In this study, perceived job security was treated as a continuous variable ranging $1-4$. 
Work satisfaction (mediator): Respondents were asked to rate their overall work satisfaction in the survey on a five-point Likert scale (1: Not satisfied, 5: Very satisfied). Work satisfaction was measured as a continuous variable ranging from 1-5.

Wish to maintain the current job (endogenous variable): The PSED asked respondents "Do you wish to maintain your current job in the future?" Respondents were asked to report a binary "yes" or "no".

Control variables: A range of demographic and work-related factors were controlled. Continuous covariates included are age, average daily work hours, monthly salary, and household size. Employment contract type (non-regular worker vs. regular worker), gender (male vs. female), marital status (married or civil partnership vs. others), head of the household (yes vs. no), and disability severity (mild vs. severe) were measured as binary variables. The PSED defined persons with severe disability as those who meet the criteria for disability classification grades 1, 2, or 3 under the Korean Act on Welfare of Persons with Disabilities and have either brain, sight, mental, heart, respiratory, cerebral palsy, or arm-related physical impairments. All others are classified as having mild disabilities. The present study used the PSED definition to distinguish between severe and mild disabilities. Self-perceived household economic class (low-, middle-, high- class), educational attainment (middle school degree or lower, high school degree, college degree or higher), and company size (10 or less, 11-100, more than 100) were measured as three-category categorical variables in this study.

\subsection{Strategy of Analysis}

To examine the pathways between workplace disability facilities, perceived workplace safety, work satisfaction, and job retention wishes, we conducted generalized structural equation modeling (GSEM) using STATA 16. GSEM modeling allows researchers to estimate different types of causation simultaneously in a multivariable model, including mediating effects. It also allows examination of simultaneous modeling of several different regression analyses. Unlike the commonly used Ordinary Least Square (OLS) analysis, which can only examine a single relationship between a dependent and an independent variable, the advantage of GSEM is that is it can examine multiple relationships simultaneously, including multiple mediational relationships. This approach aims to examine the underlying mechanisms of a relationship between a dependent and an independent variable through including a third explanatory variable (i.e., mediator) [32]. For example, in our study, we hypothesized that disability facilities (independent variable) affect perceived safety (mediator) and work satisfaction (mediator), and perceived safety and work satisfaction, in turn, affect job retention wishes (dependent variable).

Four different sets of pathway models were examined in this study (see Figure 1). Lee and Shin (2019) [27] found that individuals who worked in companies that provided more disability facilities were significantly more likely to perceive their workplaces as safe and therefore had higher work satisfaction than those who worked in companies that provided fewer disability facilities. That is, perceived workplace safety partially mediated the relationship between disability facilities and work satisfaction (presented in Figure 1 as solid black arrows). Building on Lee and Shin's (2019) study, the present study examined the relationship between disability facilities and job retention wishes, with perceived workplace safety and work satisfaction as mediators. The goal of the present study was to examine whether significant direct effects exist between (1) workplace disability facilities and job retention wishes (disability facilities $\rightarrow$ job retention wishes), (2) perceived workplace safety and present job retention wishes (perceived workplace safety $\rightarrow$ job retention wishes), and (3) work satisfaction and job retention wishes (work satisfaction $\rightarrow$ job retention wishes). Model 1 assumes that direct effects 1,2, and 3 exist. Model 2 assumes that direct effects 2 and 3 exist. Model 3 assumes that direct effects 1 and 3 exist. Lastly, Model 4 assumes that only direct effect 3 exists. Akaike information criterion (AIC) and Bayesian (or Schwarz) information criterion (BIC) were calculated to compare the fit of different models. AIC and BIC were calculated using the program in STATA 16. AIC and BIC are statistical estimators used to compare different models and find the best model. That is, given a 
collection of models for the data, AIC and BIC estimate the quality of each model, relative to each of the other models [33]. Smaller AIC and BIC values indicate a better model fit. The AIC and BIC values of each model are presented in Table 3.

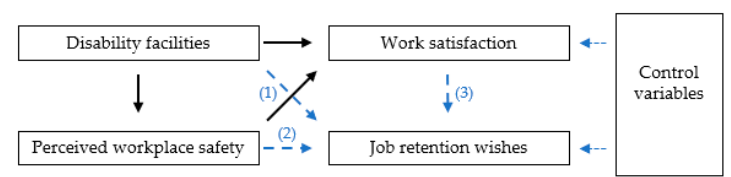

a) Model 1

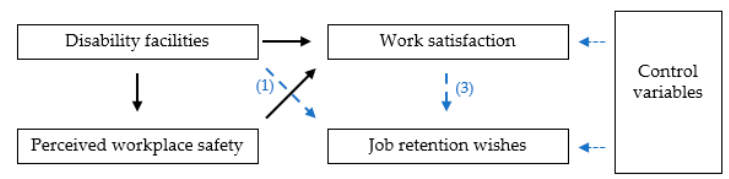

c) Model 3

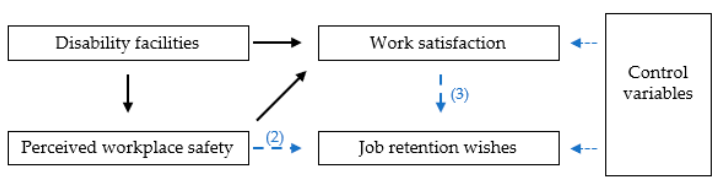

b) Model 2

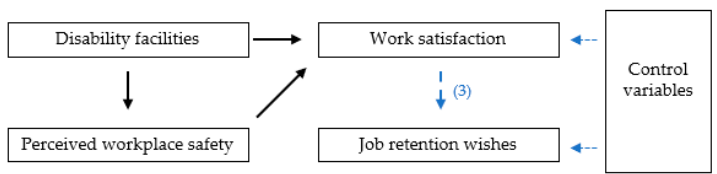

d) Model 4

Figure 1. Model comparisons. Building on Lee and Shin's (2019) [27] study (presented as solid black arrows), the present study examined the relationship between disability facilities and job retention wishes, with perceived workplace safety and work satisfaction as mediators (presented as dashed blue arrows). (a) Model 1 assumes that direct effects 1, 2, and 3 exist; (b) Model 2 assumes that direct effects 2 and 3 exist; (c) Model 3 assumes that direct effects 1 and 3 exist; (d) Model 4 assumes that only direct effect 3 exists.

\section{Results}

As presented in Table 2, descriptive results showed that respondents reported an average of 1.7 disability facilities (maximum five facilities) at workplaces. Little more than half (55\%) of the respondents reported their workplace did not provide any facilities. The prevalence of each facility was reported as follows: Approximately 33\% of respondents reported their workplaces provided suitable pavement for disabled pedestrians (i.e., adequate clear space on pavements for wheelchairs and scooters); $41 \%$ reported their workplaces provided reserved parking space for disabled employees; $31 \%$ reported their workplaces had removed vertical level changes (e.g., curbs, steps, ruts, gutters, etc.); $30 \%$ reported their workplaces had adequate entrance and doorway width for wheelchairs, and $32 \%$ reported their workplaces provided accessible bathrooms. Respondents reported an average work satisfaction of 3.5 (out of 5) and perceived workplace safety of 2.8 (out of 4). The vast majority- $95 \%$ of respondents-reported they wished to maintain their current jobs in the future.

Table 3 presents the generalized structural equation modeling results. First, results showed that respondents who worked in companies that provided more disability facilities perceived their workplace to be significantly safer $(b=0.07, p<0.001$; disability facilities $\rightarrow$ perceived safety) even after controlling for other covariates. Second, respondents whose workplaces provided more disability facilities were significantly more likely to report higher work satisfaction $(b=0.03, p<0.01$; disability facilities $\rightarrow$ work satisfaction) and those who perceived their workplaces were safer were significantly more likely to report higher work satisfaction ( $b=0.26, p<0.01$; perceived safety $\rightarrow$ work satisfaction). In total, every additional workplace disability facility had an effect of increasing work satisfaction by 0.05 (i.e., total effect), and this effect was reported to be partially mediated through respondents' perceived workplace safety. Results showed that perceived work safety mediated approximately $40 \%$ of the effect between workplace disability facilities and work satisfaction (indirect effect/total effect $=0.02 / 0.05, p<0.001)$. Third, results showed that respondents with higher work satisfaction were significantly more likely to wish to maintain their present jobs $(b=1.08, \operatorname{Exp}(b)=2.94, p<0.001$; work satisfaction $\rightarrow$ job retention wishes). On the other hand, the effects of disability facilities on respondents' wish to maintain their present jobs (disability facilities $\rightarrow$ job retention wishes) and perceived workplace safety on respondents' wish to maintain their present jobs (perceived safety $\rightarrow$ job retention wishes) were statistically insignificant. The effect of disability facilities on respondents' 
wish to maintain their present jobs was reported to be fully mediated by perceived workplace safety and work satisfaction. The AIC and BIC results confirmed that model 4, which excludes the pathways "disability facilities $\rightarrow$ job retention wishes" and "perceived safety $\rightarrow$ job retention wishes", was the best fit. The final model 4 pathway is depicted in Figure 2.

Table 2. Descriptive results of the main interest variables $(\mathrm{N}=1023)$.

\begin{tabular}{|c|c|}
\hline Variables & Mean (SD) \\
\hline Work satisfaction (1: not satisfied—5: very satisfied) & $3.52(0.61)$ \\
\hline Perceived workplace safety (1: very dangerous-4: very safe) & $2.78(0.58)$ \\
\hline \multirow[t]{2}{*}{ Number of disability facilities $(\max 5)$} & $1.63(2.11)$ \\
\hline & n (\%) \\
\hline \multicolumn{2}{|l|}{ Job retention wishes } \\
\hline No & $50(4.9 \%)$ \\
\hline Yes & $972(95.1 \%)$ \\
\hline \multicolumn{2}{|l|}{ Number of disability facilities } \\
\hline 0 & $559(54.6 \%)$ \\
\hline 1 & $72(7.0 \%)$ \\
\hline 2 & $56(5.5 \%)$ \\
\hline 3 & $50(4.9 \%)$ \\
\hline 4 & $55(5.4 \%)$ \\
\hline 5 & $232(22.7 \%)$ \\
\hline \multicolumn{2}{|l|}{ Suitable pavement for disabled pedestrians at worksites } \\
\hline No & $683(66.8 \%)$ \\
\hline Yes & $340(33.2 \%)$ \\
\hline \multicolumn{2}{|l|}{ Reserved parking space for disabled people at workplaces } \\
\hline No & $603(58.9 \%)$ \\
\hline Yes & $420(41.1 \%)$ \\
\hline \multicolumn{2}{|l|}{$\begin{array}{l}\text { Removal of vertical changes of levels (curbs, steps, ruts, gutters } \\
\text { etc.) at workplaces }\end{array}$} \\
\hline No & $702(68.6 \%)$ \\
\hline Yes & $321(31.4 \%)$ \\
\hline \multicolumn{2}{|l|}{$\begin{array}{l}\text { Adequate entrance and doorways space (i.e., width) at } \\
\text { workplaces }\end{array}$} \\
\hline No & $718(70.2 \%)$ \\
\hline Yes & $305(29.8 \%)$ \\
\hline \multicolumn{2}{|l|}{ Disability bathroom at workplaces } \\
\hline No & $696(68.0 \%)$ \\
\hline Yes & $327(32.0 \%)$ \\
\hline
\end{tabular}

Notes: Survey weights were applied to represent the population parameter.

Table 3. Generalized Structural Equation Modeling (GSEM) results.

\begin{tabular}{lcccc}
\hline & Model 1 & Model 2 & Model 3 & Model 4 \\
\hline Perceived safety $\leftarrow$ Facilities & Coef. (SE) & Coef. (SE) & Coef. (SE) & Coef. (SE) \\
\hline Work satisfaction $\leftarrow$ Facilities & $0.07(0.01)^{* * *}$ & $0.07(0.01)^{* * *}$ & $0.07(0.01)^{* * *}$ & $0.07(0.01)^{* * *}$ \\
Work satisfaction $\leftarrow$ Perceived safety & $0.03(0.01)^{* *}$ & $0.03(0.01)^{* *}$ & $0.03(0.01)^{* *}$ & $0.03(0.01)^{* *}$ \\
\hline Job retention wishes $\leftarrow$ Work satisfaction & $0.26(0.03)^{* * *}$ & $0.26(0.03)^{* * *}$ & $0.26(0.03)^{* * *}$ & $0.26(0.03)^{* * *}$ \\
Job retention wishes $\leftarrow$ Facilities & $1.00(0.24)^{* * *}$ & $1.02(0.24)^{* * *}$ & $1.04(0.24)^{* * *}$ & $1.08(0.23)^{* * *}$ \\
& 0.08 & - & 0.09 & - \\
Job retention wishes $\leftarrow$ Perceived safety & $(0.08)$ & & $(0.08)$ & - \\
& 0.21 & 0.25 & - & $-0.07(0.32)$ \\
Job retention wishes $\leftarrow$ Regular worker & $(0.25)$ & $(0.25)$ & $-0.07(0.32)$ & $-0.01(0.02)$ \\
Job retention wishes $\leftarrow$ Age & $-0.10(0.32)$ & $-0.10(0.32)$ & $0.01(0.02)$ & \\
Job retention wishes $\leftarrow$ Education attainment & $0.02(0.02)$ & $0.01(0.02)$ & & \\
\hline
\end{tabular}


Table 3. Cont.

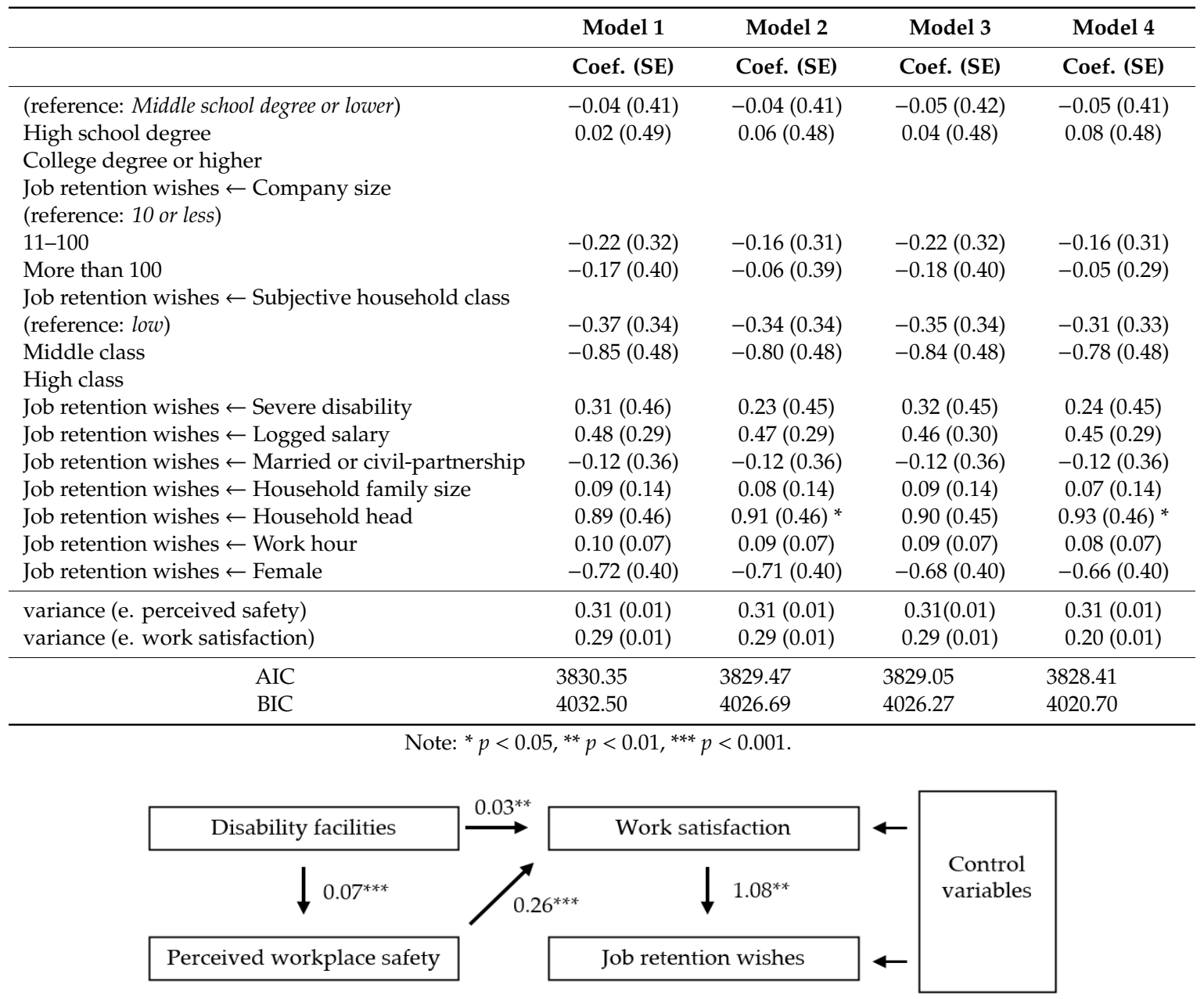

Figure 2. Parameter estimates based on Model 4. For simplicity, nonsignificant paths and error variance estimates are not shown. ${ }^{* *} p<0.01,{ }^{* * *} p<0.001$

\section{Discussion and Conclusion}

The present study examined the relationships between workplace disability accommodation features and structures, perceived workplace safety, work satisfaction, and job retention wishes among disabled workers with physical disabilities using path analysis. Pathway analysis showed that those whose workplaces provided more disability facilities were significantly more likely to perceive their workplaces to be safe and have higher work satisfaction, and hence, they were more likely to wish to maintain their present jobs in the future even after controlling for other individual and work factors, corroborating our hypothesis.

Before discussing the implications of this study, it is also important to consider the limitations of the study and directions for future study. First, the present study measured the impact of workplace disability facilities by the number of available facilities. Yet, it is unclear if having multiple facilities is always more beneficial. One or two particular facilities may have more impact than others on an individual's work retention decisions. However, with the limited information available, it is difficult to discern which facilities have a bigger impact on disabled workers' retention decisions. Hence, based on previous literature $[9,10,16,24,27]$, the present study also measured disability facilities by the number of available facilities. Future studies are needed that examine the relative influence and importance of disability facilities on disabled workers and their retention decisions. Second, the present study examined job retention wishes and not actual job retention rates due to data limitation. However, considering that some employees may have to leave their jobs involuntarily, for example, for reasons 
related to economic recession, even if they are satisfied with their work environment, we believe job retention wishes to be a more accurate barometer of disabled people's voluntary employment decisions than actual job retention rates. Lastly, the present study examined environmental building disability accommodations. Workplace disability accommodations not only include environmental building design changes but also work adjustments (i.e., reduced and flexible work hours, job restructurings such as reduced manual tasks, job coaches, and training) and provision of equipment and devices such as computers with voice recognition. Due to data limitations, we could not examine non-physical work adjustments. However, most non-physical adjustments have less relevance to perceived workplace safety than physical adjustments. In this study, we were interested in how perceived workplace safety affects future retention plans. Thus, we decided to focus on environmental building structures and features.

Despite these limitations, the study makes several important contributions. The present study is the first to empirically examine how workplace disability facilities influence disabled workers' job retention decisions on a national scale in Korea. Also, using pathway analysis, the present study is the first to examine how perceived workplace safety and work satisfaction mediated this relationship. Several implications can be drawn from this study.

First, study results showed that the majority of respondents reported that their workplaces did not provide disability facilities. Only $30 \%$ of respondents reported their workplaces had adequate entrance and doorways for wheelchair accessibility, and 32\% reported their workplaces had disability bathrooms. Approximately $41 \%$ of respondents reported their workplaces provided reserved parking spaces for disabled employees and 31\% reported their workplaces removed vertical changes of levels for easy access. The "Act on the Guarantee of Convenience Promotion of Persons with disabilities, Senior citizens, Pregnant women and Nursing mothers" stipulates that all public buildings and facilities, as well as factories with a total floor area larger than $500 \mathrm{~m}^{2}$, are mandated to install disability-accommodating facilities. However, according to a 2017 survey report [9], only $25 \%$ of disabled workers were reported as factory workers, and the majority were reported as either service and sales workers or office workers; as a result, their workplaces were not obligated to provide disability facilities as mandated under the Act. Also, among disabled factory workers, approximately $30 \%$ worked in companies with fewer than 10 employees; hence, their workplaces are likely to be less than $500 \mathrm{~m}^{2}$ [9]. In the UK, under the Equality Act 2010, all employers, regardless of company size or industry are obligated to make reasonable adjustments to accommodate disabled employees [34]. The government "Access to Work" grant helps fund the adjustments [35], which lightens the burden on employers that employ the disabled and make the adjustments. As a result, according to a 2009/10 UK survey, which examined the socioeconomic experiences of disabled population in the UK, only $4 \%$ of disabled respondents reported that lack of disability facilities and difficulties accessing buildings were barriers to employment [36]. Likewise, Australia has a similar program, the Employment Assistance Fund (EAF), to cover the cost of making workplace changes [37]. The Korean government should consider revising the law to include more private workplace buildings for which disability facilities are mandated and also consider developing a public grant, which funds the cost of modifications. Currently, in Korea, responsibility for making modifications falls entirely on the employer.

Second, results showed that the relationship between workplace disability facility and job retention wishes were fully mediated through perceived workplace safety and work satisfaction, and no significant direct effect existed between disability facilities and job retention wishes (disability facilities $\rightarrow$ job retention wishes). If we ran an OLS analysis, instead of a path analysis, between workplace disability facility and job retention wishes, the effect of workplace disability facility on job retention wishes would have been insignificant, providing an inaccurate picture of the dynamic. By using path analysis, we proved that there is a positive relationship between workplace disability facility and job retention, and that it is fully mediated by perceived work safety and work satisfaction. Based on our findings, we know workers whose companies provided more disability facilities were significantly more likely to perceive their workplaces as safer and hence, are more likely to have higher work satisfaction, 
and therefore, more likely to stay at their present jobs. Such findings provide incentives to policymakers and employers to implement better workplace disability facilities and related policies.

Third, it is important to note that the majority of $95 \%$ of respondents reported that they wished to maintain their current jobs in the future (see Table 2), which may be due to the high unemployment rate among disabled population. This may also be a reason behind the no direct effect between disability facilities and job retention wishes. The majority of workers are likely to wish to maintain their current jobs regardless of workplace disability facilities because of the high level of unemployment among disabled population, and the relationship between job retention wishes and disability facilities becomes significant only when factors such as work satisfaction and perceived work safety are also taken into consideration.

The 2030 Agenda for Sustainability Development, which was adopted by all UN member states in 2015, pledged to end poverty in all forms and ensure "no one is left behind". Disabled people face an increased risk of poverty due to barriers to paid work. Making workplaces more accessible is important to securing disabled people's economic stability and independence. Our study findings indicate that Korea still has much progress to make in this area. Despite our findings that disability facilities help increase disabled workers' perceived safety, work satisfaction, and job retention, more than half of the respondent disabled workers indicated that their workplaces did not provide any disability facilities. The authors urge the development of policies that better address workplace disability facilities and accessibility for the disabled.

Author Contributions: Conceptualization, E.J.K. and M.J.K.; methodology, E.J.K. and M.J.K.; formal analysis, E.J.K.; writing original draft preparation E.J.K. and M.J.K; writing review and editing E.J.K. and I.K.; supervision M.J.K.; funding acquisition I.K. All authors have read and agreed to the published version of the manuscript.

Funding: This research was supported by a grant (20AUDP-B127891-04) from the Architecture \& Urban Development Research Program funded by the Ministry of Land, Infrastructure and Transport of the Korean government.

Conflicts of Interest: The authors declare no conflict of interest.

\section{References}

1. United Nations. Transforming Our World: The 2030 Agenda for Sustainable Development. 2015. Available online: https://sustainabledevelopment.un.org/post2015/transformingourworld/ (accessed on 6 March 2020).

2. United Nations Development Programme. What Does It Mean to Leave no One Behind? 2018. Available online: https://www.undp.org/content/undp/en/home/librarypage/poverty-reduction/what-doesit-mean-to-leave-no-one-behind-.html (accessed on 6 March 2020).

3. Richardson, L. The 2030 Agenda:'Leave No Person with Disabilities Behind. 2017. Available online: https://www.undp.org/content/undp/en/home/blog/2017/1/19/The-2030-Agenda-Leave-no-person-withdisabilities-behind.html (accessed on 3 March 2020).

4. United Nations. Realization of the Sustainable Development Goals by, for and with Persons with Disabilities. 2018. Available online: https://www.un.org/development/desa/disabilities/wp-content/uploads/sites/15/2018/ 12/UN-Flagship-Report-Disability.pdf (accessed on 3 March 2020).

5. United Nations. Convention on the Rights of Persons with Disabilities (CRPD). Available online: https:/www.un.org/development/desa/disabilities/convention-on-the-rights-of-persons-with-disabilities/ convention-on-the-rights-of-persons-with-disabilities-2.html (accessed on 3 March 2020).

6. The Republic of Korea Policy Brief, Korean Sustainable Development Goal. Available online: http://www. korea.kr/special/policyCurationView.do?newsId=148867900 (accessed on 13 April 2020).

7. Korean Statistics Office: Employment Rate. Available online: http://www.index.go.kr/unify/idx-info.do? $\mathrm{idxCd}=8008$ (accessed on 3 March 2020).

8. Park, H. The Core of Disabled People's Independence Lies with Securing Their Employment. Kyeopbup Daily, 13 February 2020. Available online: https://www.kyongbuk.co.kr/news/articleView.html?idxno=2030295 (accessed on 3 March 2020). 
9. Lee, J.; Seo, J. The Effects of the Disability Anti-Discrimination Law on the Job Tenure of Disabled Workers: Focusing on the Mediating Effects of Job Satisfaction. Disabil. Employ. 2014, 24, 67-95. [CrossRef]

10. Kim, Y.; Jeon, Y. A study on the status of facilities for the disabled and the effect of employment. Disabil. Employ. 2013, 23, 141-163. [CrossRef]

11. Lee, K.; Kang, B. A Study on the Improvement Direction of Barrier-Free Certification Evaluation Items -Focusd on the Evaluation Items of the Building. Korea Inst. Healthc. Archit. 2011, 17, 25-37.

12. Banks, L.M.; Hameed, S.; Usman, S.K.; Kuper, H. No One Left Behind? Comparing Poverty and Deprivation between People with and without Disabilities in the Maldives. Sustainability 2020, 12, 2066. [CrossRef]

13. Nam, C. The employment situations of the disabled and some suggestions for policy reform. J. Soc. Policy 2008, 33, 31-59. [CrossRef]

14. Lee, K. Analysis of Unemployment Hazard rate of People with Disabilities-Unemployment Duration \& its Determinants. J. Rehabil. Res. 2010, 14, 175-194.

15. Shin, H. Occupational Status Attainment: Differences between people with psychiatric disabilities and people without psychiatric disabilities. J. Vocat. Rehabil. 2009, 19, 146-166.

16. Kim, Y.; Kang, D.; Kim, Y.; Ahn, T.; Lee, M. The Study on Solution Plan of the Employment-Stability E Security for the People with Disabilities in Workplace; Employment Development Institute: SeungNam, Korea, 2014.

17. Morris, J. Pride Against Prejudice: Transforming Attitudes to Disability; London Women's Press: London, UK, 1991.

18. Magrin, M.; Marini, E.; Nicolotti, M. Employability of Disabled Graduates: Resources for a Sustainable Employment. Sustainability 2019, 11, 1542. [CrossRef]

19. Zwerling, C.; Sprince, N.L.; Davis, C.S.; Whitten, P.S.; Wallace, R.R.; Heeringa, S.G. Occupational injuries among older workers with disabilities: A prospective cohort study of the Health and Retirement Survey, 1992 to 1994. Am. J. Public Health 1998, 88, 1691-1695. [CrossRef] [PubMed]

20. Zwerling, C.; Whitten, P.S.; Davis, C.S.; Sprince, N.L. Occupational Injuries Among Older Workers with Visual, Auditory, and Other Impairments. J. Occup. Environ. Med. 1998, 40, 720-723. [CrossRef] [PubMed]

21. Zwerling, C. Occupational Injuries Among Workers with Disabilities. JAMA 1997, 278, 2163. [CrossRef] [PubMed]

22. Walters, G.J. Equal Access: Safeguarding Disability Rights; Rourke Corp: Apopka, FL, USA, 1992.

23. World Health Organization. World Report on Disability: World Health Organization. 2011. Available online: https://www.who.int/disabilities/world_report/2011/en/ (accessed on 6 March 2020).

24. Park, J.; Heo, S.; Jeong, T. The influence of working-condition of disabled paid-workers on job satisfaction, and life-satisfaction on the job. Disabil. Employ. 2011, 21, 167-186.

25. Kim, B.; Nam, Y. Determinants of Employment for the People with Disability in Enterprise. Disabil. Employ. 2014, 24, 190-221.

26. Kim, J. Impacts of working environment characteristics in the business sector on the voluntary turnover of disabled worker. Korean Public Adm. Rev. 2017, 51, 157-184. [CrossRef]

27. Lee, M.; Shin, H. Convenience facilities and job satisfaction of employees with disabilities: Perceived safety as a mediator. Disabil. Employ. 2019, 29, 5-30. [CrossRef]

28. Panel Survey of Employment of the Disabled (PSED). Available online: https://edi.kead.or.kr/Contents.do? $\mathrm{cmd}=\_051$ A\&mid=213 (accessed on 3 March 2020).

29. Achieve Australia. What is a Physical Disability? Available online: https://achieveaustralia.org.au/ndisoverview-and-faqs/physical-disability/ (accessed on 3 March 2020).

30. Korean National Law Information Center. The Korean Act on Welfare of Persons with Disabilities. Available online: http://www.law.go.kr/lsInfoP.do?lsiSeq=211959\&efYd=20200604\#0000 (accessed on 3 March 2020).

31. Song, C. 2018 Average Wage-Earning Workers Monthly Income KRW 2970 Thousand: Average Gap 2 Times Among Big-Medium-Small Companies. DongAh Daily, 23 January 2020. Available online: http: //www.donga.com/news/article/all/20200122/99370762/1 (accessed on 3 March 2020).

32. Iacobucci, D. Quantitative Applications in the Social Sciences: Mediation Analysis; SAGE Publications: Thousand Oaks, CA, USA, 2008.

33. Aho, K.; Derryberry, D.; Peterson, T. Model selection for ecologists: The worldviews of AIC and BIC. Ecology 2014, 95, 631-636. [CrossRef] [PubMed] 
34. Nibusinessinfo. Disabled Access and Facilities in Business Premises. Available online: https:// www.nibusinessinfo.co.uk/content/improve-access-and-use-facilities-disabled-employees (accessed on 3 March 2020).

35. Nidirect Government Services. Access to Work-Practical Help at Work. Available online: https://www. nidirect.gov.uk/articles/access-work-practical-help-work (accessed on 3 March 2020).

36. Vince, L.; Willitts, M.; Farmer, M.; Gunning, C. Life Opportunities Survey: Wave One Results, 2009/11. 2011. Available online: www.odi.gov.uk/los (accessed on 3 March 2020).

37. Australian Network on Disability. Workplace Adjustments. Available online: https://www.and.org.au/pages/ workplace-adjustments.html (accessed on 3 March 2020).

(C) 2020 by the authors. Licensee MDPI, Basel, Switzerland. This article is an open access article distributed under the terms and conditions of the Creative Commons Attribution (CC BY) license (http://creativecommons.org/licenses/by/4.0/). 